\title{
Concertación para una nueva economía popular
}

\author{
Aquiles Montoya
}

\section{Introducción}

Escribiamos hace algún tiempo: "Es precisamente el desgarramiento social el que históricamente conduce a los pueblos a los pactos sociales; y solamente cuando los distintos actores sociales interiorizan que el curso de los hechos conduce a la auto-destrucción, que la concertación se convierte en una idea-Iuerza". "Afortunamente con el Foro de Concertación Económica y Social, nos aprestamos a realizar tal experiencia inédita en nuestro pais, desalortunadamente los sujelos concertantes, en to que a los trabajadores se reliere, es tan general que podría reducirse a tan solo los trabajadores asalariados del sector público y privado capitalista, to cual dejarla por fuera a un sector mayoritario de nuestra población: esto es, a todos aquellos que se ubican en lo que llamaremos economia popular y para quienes la concertación se convierte en un elemento clave a fin de Iransformar tal economía en una Nueva Economia Popular.

En el presente trabajo intentaremos mostrar la importancia cuantitativa que representa este sector de nuestra sociedad y la peculiaridad de sus intereses, ambos factores a una juslitican la necesidad de su participación en el Foro. Adicionalmente, presentaremos cuales son sus principales problemas, carencias y necesidades, asi como su aporte al desarrollo económico y social, lo cual nos mostrará lo legílimo de la concerlación con esle sector social. Finalmenle presentaremos algunas

- Monloya, Aquiles. "La Concertación Nacional: Una Necesidad Imposlergable". Revista ECA. Sepliembre, 1990. 
propuestas temáticas acerca del qué concertar a fin de avanzar hacia la concertación de la Nueva Economía Popular.

\section{Importancla cuanthatlva de la economia popular}

Cuando hablamos de economía popular hacemos referencia a las dislintas actividades de la producción material e inmaterial, asi como de la circulación, con carácter no capitalistas. Descriptivamente nos estamos reliriendo a los pequenos productores del sector agropecuario, asi como al denominado sector informal urbano (SIU).

Algunos indicadores de tal economía popular en el agro podernos encontrarlas en las explotaciones menores de $10 \mathrm{mz}$. trabajadas en propiedad, las cuales para 1987 ascendian a 212,082 explotaciones, representando el $86.1 \%$ del tolal de explotaciones en propiedad en el sector no reformado y por otra parte 32,962 explotaciones menores de $10 \mathrm{mz}$. trabajadas en arrendamiento constituyendo el $94.9 \%$ del total de explotaciones arrendas en el sector no reformado. Ver Cuadro $\mathrm{N}^{2} 1$.

Cuadro $N^{2} 1$

Número de explolaciones en propiedad y arrendamiento menores de $10 \mathrm{mz}$ en el Sector No Retormado, 1987

\begin{tabular}{|c|c|c|}
\hline & Propiedad & Arrendamiento \\
\hline $\begin{array}{rr}0 & 2 \mathrm{mz} \\
2 & 5 \mathrm{mz} \\
5 & 10 \mathrm{mz} \\
\end{array}$ & $\begin{array}{r}145,575 \\
41,276 \\
25,231 \\
\end{array}$ & $\begin{array}{r}32,794 \\
3,238 \\
1,930 \\
\end{array}$ \\
\hline Tolal & 212,082 & 37,962 \\
\hline
\end{tabular}

Fuente: MAG-OSPA. "Estudio Nacional del Sector Agropecuario. Encuesta sobre Uso y Tenencia de la Tierra", 1989.

Si suponemos que a cada explotación en propiedad o en arrendamiento corresponde una familia rural estamos hablando de 250,000 familias o de 1.5 millones de personas, cuyos intereses, problemas y aportes no coinciden necesariamente con los de los trabajadores asalariados del sector público o privado, al menos, no en tanto que productores.

En cuanio al Seclor Iniormal Urbano (SIU) se cuentan con datos más precisos y más recientes, para 1990 encontramos que del tolal de ocupados urbanos el $50.8 \%$ se encuentra en el SIU.

Siendo su importancia relativa muchísimo mayor en actividades lales como: agricultura, industria, comercio y Iransporte. (Ver Cuadro $N^{2} 2$ ) 
Cuadro $\mathrm{N}^{2} 2$

Ocupados por sector de ocupación y rama de actividad económica*. Sector urbano 1990

\begin{tabular}{|c|c|c|c|c|c|c|c|c|c|c|}
\hline & & Agrleul. & Mineria & Indust. & $\begin{array}{c}\text { Elec. gas } \\
\text { y agua }\end{array}$ & Const. & Comerclo & $\begin{array}{l}\text { Transp. } \\
\text { y Com. }\end{array}$ & $\begin{array}{c}\text { Eot. } \\
\text { Econom. }\end{array}$ & Serv. \\
\hline \multicolumn{11}{|c|}{ (Valores absolutos) } \\
\hline & TOTAL & & & & & & & & & \\
\hline $\begin{array}{l}\text { Sector } \\
\text { modemo }\end{array}$ & 408,520 & 30,542 & 516 & 95,968 & 5,196 & 27,255 & 58,501 & 21.933 & 21,647 & 146,962 \\
\hline $\begin{array}{l}\text { Sector } \\
\text { informal }\end{array}$ & 422,274 & 35,375 & 79 & 100,208 & 255 & 27,114 & 184,602 & 25,317 & 1.929 & 47,634 \\
\hline TOTAL & 831,033 & 65.917 & 595 & 196,176 & 5,451 & 54,369 & 243,103 & 47,250 & 23,576 & 194,596 \\
\hline \multicolumn{11}{|c|}{ (Porcentajes) } \\
\hline $\begin{array}{l}\text { Sector } \\
\text { moderno }\end{array}$ & 49.2 & 46.3 & 86.7 & 48.9 & 95.3 & 50.1 & 24.1 & 46.4 & 91.8 & 75.5 \\
\hline $\begin{array}{l}\text { Sector } \\
\text { intormal }\end{array}$ & 50.8 & 53.7 & 13.3 & 51.1 & 4.7 & 49.9 & 75.9 & 53.6 & 8.2 & 24.5 \\
\hline TOTAL & 100.0 & 100.0 & 100.0 & 100.0 & 100.0 & 100.0 & 100.0 & 100.0 & 100.0 & 100.0 \\
\hline
\end{tabular}

Fuente: MIPLAN-UIM. Encuesta de Hogares de Propósitos Múltiples. Total pais urbano. 1990.

- NO SE INCLUYE: SERVICIO DOMESTICO. 


\section{Cuadro $\mathrm{N}^{2} 3$}

Ocupados por sector de ocupación y rama de actividad económica*. Sector urbano 1988

\begin{tabular}{|c|c|c|c|c|c|c|c|c|c|c|}
\hline & TOTAL & Agrleul. & Mineria & Induel. & $\begin{array}{c}\text { Eloc. gas } \\
\text { y egue }\end{array}$ & Conal. & Comerclo & $\begin{array}{l}\text { Tranep. } \\
\text { y Com. }\end{array}$ & $\begin{array}{c}\text { Est } \\
\text { Econom. }\end{array}$ & Serv. \\
\hline & \multicolumn{10}{|c|}{ (Valores absolulos) } \\
\hline $\begin{array}{l}\text { Sector } \\
\text { moderno }\end{array}$ & 388,023 & 31,770 & 258 & 91,551 & 4,991 & 27,379 & 52,363 & 22,900 & 20,881 & 135,930 \\
\hline $\begin{array}{l}\text { Sector } \\
\text { intormal }\end{array}$ & 277,373 & 26,044 & 84 & 63,864 & 166 & 16,798 & 122,848 & 16,176 & 798 & 30,595 \\
\hline \multirow[t]{2}{*}{ TOTAL } & 665,396 & 57,814 & 342 & 155,415 & 5,157 & 44,177 & 175,211 & 39,076 & 21,679 & 166,525 \\
\hline & \multicolumn{10}{|c|}{ (Porcentajes) } \\
\hline $\begin{array}{l}\text { Sector } \\
\text { moderno }\end{array}$ & 458.3 & 55.0 & 75.4 & 58.9 & 96.8 & 62.0 & 30.0 & 58.6 & 96.3 & 81.6 \\
\hline $\begin{array}{l}\text { Sector } \\
\text { informal }\end{array}$ & 41.7 & 45.0 & 24.6 & 41.1 & 3.2 & 38.0 & 70.0 & 41.4 & 3.7 & 18.4 \\
\hline TOTAL & 100.0 & 100.0 & 100.0 & 100.0 & 100.0 & 100.0 & 100.0 & 100.0 & 100.0 & 100.0 \\
\hline
\end{tabular}

Fuente: MIPLAN-UIM. Encuesta de Hogares de Propósilos Múltiples. Total pals urbano. 1988.

- NO SE INCLUYE: SERVICIO DOMESTICO. 
Tenemos, pues, que del total de 831,031 ocupados residentes en el sector ubano, 422,274 se ubican en el Seclor Intormal Ubano. Y visla lal realidad en cuanto a su tendencia, comparando los datos de 1988 con los de 1990, lenemos que el Sector Moderno sólo vió incrementar su número en 20,497 , mientras que el SIU se incrementó en 144,901. Lo que provocó que, de representar el $41.7 \%$ de los ocupados urbanos en 1988, pasara a representar el $50.8 \%$ en 1990. (Ver Cuadro $N^{2} 2$ y el № 3).

Por otra parte, al observar la eslructura ocupacional del SIU para 1990, encontramos que más del $50 \%$ lo conslituyen los ocupados bajo la categorla de "cuenta propia", o sea que mayoritariamenle se trata de "empresas" unipersonales, to cual implica que existe una atomización desmedida, siendo ello más significalivo en el comercio, la industria y los servicios.

Retornando a las categorias ocupacionales, además de los ocupados por cuenta propia encontramos a los asalariados temporales (18.2\%) y a los familiares 110 remunerados $(12.1 \%)$. Los asalariados permanentes sólo represenlan el $9.4 \%$ del lolal de ocupados en el SIU. (Ver Cuadro $\mathrm{N}^{a}$ 4).

Como se puede apreciar a partir de los datos presentados los inlegrantes de la economia popular poseen una importancia cuanlitaliva muy significativa y si a ello anadimos su peculiaridad de ser empresarios no capitalistas, que autogeneran mayoritariamente sus puestos de trabajo y que operan y se multiplican, incluso, a pesar de la apolílica económica del régimen, es obvio que se Irata de un sector de nuestra sociedad que debe de estar presente en el Foro de Concertación Económica y Social a fin de hacer oir sus problemas, sus necesidades y sus intereses.

La economia popular en nuestro pais es quien ha cargado secularmente con la responsabilidad de importantes aclividades económicas orienladas principalmente a satisfacer las necesidades de bienes y servicios de las mayorías populares y con ello, no sólo ha contribuido a la reproducción material de la fuerza de trabajo, sino que ha posibilitado que siga funcionando el sistema aún en sus momentos de mayor crisis. Cuando el capital buscó refugiarse en el extranjero cerrando centros de trabajo y dejando desabaslecida a la sociedad, fue la economla popular la que cumplió un excelenle papel de relevo, no sólo llenando los espacios vacios dejados por el capital sino generando sus propias ocupaciones.

Y la economia popular ha operado sin incentivos, ni medidas proteccionistas de parte del eslado, obteniendo muy bajos excedentes pero funcionando pese a todas las adversidades. Los aulénticos empresarios 
Cuadro 4

Ocupados en el secior informal urbano por categoría ocupacional y sexo*

(Valores absolutos)

\begin{tabular}{lrrrrrr} 
& Total & Patrono & Cta. Propla & $\begin{array}{c}\text { Fam. no } \\
\text { remunerado }\end{array}$ & $\begin{array}{c}\text { Asal. perma- } \\
\text { nente }\end{array}$ & Asal. temporal \\
\hline Total & 422,513 & 19,870 & 234,681 & 51,076 & 39,790 & 77,096 \\
Hombres & 212,274 & 14,951 & 89,069 & 19,795 & 25,409 & 63,050 \\
Mujeres & 210,239 & 4,919 & 145,612 & 31,281 & 14,381 & 14,046 \\
& \multicolumn{7}{c}{} & (Porcentajes) \\
Total & 100.0 & 4.7 & 55.5 & 12.1 & 9.4 & 18.2 \\
Hombres & 100.0 & 7.0 & 42.0 & 24.1 & 12.0 & 29.7 \\
Mujeres & 100.0 & 2.3 & 69.3 & 14.9 & 6.8 & 6.7 \\
\hline
\end{tabular}

Fuente: IBID, cuadro anterior

- NO SE INCLUYE: SERVICIO DOMESTICO 
de nuestro pais no son aquellos que operan sólo bajo condiciones venlajosas y que claman por el auxilio del Eslado cuando se ven en dificullades, los auténticos empresarios se encuentran en la economla popular; han sido ellos quienes con su esluerzo físico y mental, con su ingenio y largas jornadas de Irabajo los que han mantenido a nuestra economia funcionando en las terribles condiciones de una guerra civil como la que hemos vivido y sufrido.

Siendo ésto así, la economia popular requiere de una auténtica represenlatividad en el Foro de Concertación Económico y Social a fin de que se tomen los acuerdos necesarios que posibiliten su potenciación, desarrollo y ullerior transformación en una Nueva Economía Popular.

\section{Algunos problemas de la economia popular}

Los problemas que enfrenta este sector de nuestra sociedad son múltiples y diversos como las actividades a que se dedican sus miembros, asi tenemos que en la agricultura, por ejemplo, su problemálica es observable desde la insuficienle tierra para su cultivo, asi como la pobre calidad de la misma, hasla los conocidos problemas de falla de crédito suliciente, oportuno y en condiciones favorables y el sesgo en cuanto a los precios, lodo ello se conjuga para que no logren incrementar la productividad de su trabajo, que vayan perdiendo afio tras ano la posibilidad de su reproducción material, aunque se aferren a su parcela con la perseverancia de quien no posee olra allernativa para vivir.

No es muy diferente la problemálica de quienes se dedican a las actividades manulactureras y mercanliles, la lalta de condiciones materiales para su actividad la compensan con un mayor desgaste físico, en el cual, a menudo se involucra loda la familia, a fin de oblener un mísero ingreso que les ayude a "irla pasando".

De manera general la economía popular se ha caracterizado por eslar en función de los intereses directos y/o indireclos del capital genéri$c_{0}$, de alli que haya sido sistemálicamente expoliada, lo cual ha limitado sus posibilidades de desarrollo y reproducción en escala ampliada, a tal realidad ha contribuído su carácler atomizado, su individualismo alienante y la despreocupación por parte del Estado.

Para los integranles de la economia popular, su actividad se ha reducido a una mera estrategia de sobrevivencia, ante la incapacidad del sistema de generar suficientes pueslos de Irabajos remunerados, de alli que nunca hayan concebido como real y posible el convertirse en una aulénlica luerza social capaz de mejorar sus condiciones de vida y de trabajo. Con tantas y lantas necesidades insatisfechas más les ha pre- 
ocupado el oblener los alimentos del dia presente que pensar en encontrar altemativas de solución para su realidad. Es más, cuando se han emprendido estudios de este sector pese a que se han detectado sus principales problemas nunca se han ofrecido soluciones integrales que es precisamente lo que requiere este sector, de lo contrario se seguirá con simple paliativos que para lo único que sirven es para prolongar sus miserables existencias.

Pero además de los problemas estrictamente económicos, los miembros de la economia popular suiren los males de la carencia de una necesaria y suficiente organización, lo cual les vuelve más vulnerables y menos eficientes a la hora de presentar sus demandas. A su vez es el sector con mayor problemas sociales: carencia de viviendas adecuadas y los necesarios servicios de agua, electricidad y eliminación de excretas, to cual viene a agravar sus problemas de salud, irente a la carencia de un sistema de prestación de servicios vinculados a la misma, ya que no tienen acceso al ISSS y lo mismo puede decirse en to que respecla a la educación, en general se trala del Sector Social donde el anallabetismo es mayor y los niveles de escolaridad son los más bajos.

En consecuencia, nos encontramos ante un fragmento mayorilario de nuestra población que está marginada socialmente y que pudiera ser maginada del Foro de Concertación Económica y Social, debido a su peculiar forma de existencia y de reproducción. Así tenemos, por ejemplo, que un acuerdo relerido a un incremento salarial en nada beneficiaría a este sector mayoritario de nuestra sociedad porque primariamente no son asalariados; o bien, un acuerdo de congelamienlo de precios de alimentos básicos, lejos de beneficiarles les perjudicaría porque sus coslos de producción se incrementarian pero no sus precios de venla.

De lo anteriormente descrito puede perlectamente colegirse que aún siendo considerados como "empresarios", tienen muy poco en común con los empresarios capitalistas, pero a su vez sus intereses no son coincidentes con los asalariados del sector público y privado, aunque pudieran tener un mayor grado de alinidad con éstos en tanto que ellos son también trabajadores direclos.

Ante esta realidad tan peculiar que presentan los integrantes de la economía popular, además de su heterogenidad, dependiendo de la rama de la actividad económica en que se desenvuelven, así como si se trata de habitantes del área urbana o rural, ciertamente, que no resulta lácil el sugerir una agenda de concertación. Pese a ello, la misma realidad se ha encargado de presenlar una alternativa; potencialmente ya existe to que sería la solución altemaliva para este sector mayoritario de la población salvadorena, esto es, lo que denominamos Nueva Economia Popular. 


\section{La Nueva Economla Popular una estrategla alternatha*}

La nueva economla popular para llegar a constituirse en tal, requiere de una reproducción en escala ampliada, de tal manera que el excedente distribuible a futuro sea suficiente para satisfacer las necesidades materiales y espirituales de sus miembros, lo cual nos indica la necesidad de generar e incrementar el excedente presente, lo que a su vez nos lleva a la necesidad de incrementar la productividad del trabajo. ¿Será ello posible? Seguramente que sl, si se cuentan con los factores posibilitamles tales como: apoyo financiero, asistencia lécnica, capacitación formal y administrativa. Además de una política fiscal y comercial que estimule y proteja a este seclor mayoritario de nuestra población. Pero adicionalmenle como se trata de unos agentes que tienen presencia en la mayorla de ramas de la actividad económica, una forma de fortalecer su desarrollo seria mediante su integración inter-sectorial e inter-ramal. Lo cual estaría exigiendo la creación de sus propias instiluciones tinancieras, esto es, loda una red de bancos comunales, o bien, un sistema financiero popular que manejara distintas lineas de crédito para las dislintas actividades económicas de la Nueva Economía Popular, así como crédito para vivienda, transporle comercial, consumo, etc. También se requeriría de un sistema de Capacitación Técnica y Administrativa, el cual podría funcionar como una fundación dedicada, exclusivamente, a los sectores populares del campo y de la ciudad; de igual manera se requeriría de un Cenlro de Coordinación y Planificación de los distintos esfuerzos orientados hacia los sectores populares, de tal manera que se evitara la duplicación del trabajo así como los males de confiar ciegamente en la asignación de recursos provocada por el mercado. Este Centro de Coordinación y Planificación, podría estar dirigido por represenlantes de los diferentes ONGs, que realizan labores de apoyo y auxilio comunitario, asi como representantes de las diversas iglesias o $\infty n-$ gregaciones religiosas que ya cuenlan con experiencia en trabajos comunitarios con marginados, relugiados, desplazados y repatriados, ya que es precisamenle en estos núcleos poblacionales donde se ha ido generando esla nueva experiencia que una vez exlendida y desarrollada, podría conformar la denominada Nueva Economia Popular, además de otras experiencias en materia de cooperativas a nivel nacional que para 1989, conlaban con nada menos que 92,777 socios. (Ver Cuadro $N^{2} 5$ ).

- Véase también: Montoya, Aquiles. "La Nueva Economla Popular ¿Una Utopia Realizable?" Revista Realidad Económica Social. Sept.-Octubre, 1991. 
Cuadro № 5

Número de Cooperativas y Asociados

según actividad económica, 1989.

\section{Cooperallvas}

Soclos

Asociaciones de Cooperalivas

de Ahorro y Crédito

352

16,949

Asociaciones Cooperativas

de Producción Agropecuaria

1,396

68,673

Asociaciones Cooperativas de

Producción Manufacturera

38

1,239

Asociaciones Cooperativas de

Producción Pesquera

Asciaciones Cooperativas

de Servicios de Transporte

Asociaciones Cooperativas

de otros servicios

Asociaciones Cooperativas

de Consumo

ATTOTAL

Fuente: Pedro Juan Hernández R. "La situación actual del cooperativismo en El Salvador". CSUCA /INVE/COACES.

Si al sector cooperalivo, ańadimos las distintas repoblaciones, asi como numerosos proyectos de comunidades atendidos por congregaciones religiosas y entidades laicas es claro que existe ya, como una realidad inédita y poco conocida aún, lo que serviría de base y fundamento para una Nueva Economia Popular lo que se requiere por ello es que se reconozca que la NEP es una estrategia alternativa de y para las mayorías populares, capaz de contribuir de manera mucho más significativa al crecimiento económico del pais y al desarrollo social de sus integrantes.

Adicionalmente, se requiere del gobierno apoyo material y legal en cuanto a la creación del Sistema Financiero Popular, al Sistema de Capacilación Técnica y Administrativa e igualmente, en cuanto al Centro de Coordinación y Planificacón de la Nueva Economia Popular, las tres inslituciones deberían de funcionar como corporaciones de utilidad pública, con londos provenientes del Eslado y de organismos internacionales. 
Tales instituciones podrlan reemplazar a un cúmulo de esfuerzos que realiza el Estado de manera descoordinada y a menudo más con fines políticos que de beneficio a los sectores populares, asl como otras muchas organizaciones e instituciones de la sociedad civil que aún no logran la necesaria unidad a lin de evilar la duplicación del trabajo con las comunidades.

Es vital para que la economía popular se transtorme en una Nueva Economia Popular, además de incrementar la productividad del trabajo, incrementar la eliciencia administrativa y comercializadora, mejorar la calidad de sus productos y servicios, asi como la inlegración en sí misma a fin de lograr un crecimienlo aulogenerado y dinámico, lodo ello contribuiría decididamenle a una reproducción en escala ampliada de la Nueva Economia Poular, lo cual traería como consecuencia una mayor generación de ingresos y de nuevos pueslos de trabajo.

Ahora bien para superar el carácler atomizado e individualista de la actual economia popular se requieren formas de organización cooperalivas, asociativas o comunilarias, 10 cual presenla múltiples ventajas para acceder al crédito, a la asistencia lécnica, a la educación formal o administrativa, asi como para lograr mejores precios en la compra como en la venta de productos y servicios; y de igual manera para presionar al gobierno en cuanto a la política económica (tributaria, arancelaria, comecial, crediticia, elc.), asi como para compartir los beneficios economicos y sociales de manera equitaliva.

Si concebimos a la Nueva Economía Popular como un lodo inlegrado, aunque sin pretensiones de aularquía, es claro que la fuenle de su dinamismo estaria en si misma, lo que haría que la misma salisfacción de las necesidades sociales de sus integrantes se convirtiera en un estimulador de mayor crecimiento. Hasta ahora la satisfacción de necesidades sociales de las mayorias populares se ha vislo como una actividad aislada de sus actividades económicas, lo cual no ha posibilitado estimular su desarrollo y no ha pasado de un mero asistencialismo. Para comprender lo que deseamos decir, pensemos en un programa masivo de vivienda popular, en el cual no solo participan con su mano de obra los beneficiarios, sino que adicionalmenle, los principales materiales para las viviendas son producidos o importados y comercializados por la Nueva Economia Popular. Es obvio, que para hacer eslo viable se requeriria de la participación del Centro de Coordinación y Planilicación, desde el diseño de las viviendas hasta la cuanlificación de los materiales necesarios, asi como la asignación de los materiales producibles por la NEP.

Ello, podria dar lugar al aparecimiento de nuevas actividades, lales como la de los "chalarreros"; no es posible producir hierro, pero si es 
posible realizar acopio de chatarra, la cual posteriormenle se podrla encargar su fundición. Por qué importar cerraduras si ellas es posible producirlas nacionalmente en talleres de metal-mecánica. Oú́ sentido tienen las ventanas de aluminio y vidrio, cuando se pueden producir artesanalmente de otros materiales? Acaso las cooperativas caneras no podrían incursionar en la agroindustria y procesar el bagazo de la cana y usarse en las viviendas. De contarse con una demanda asegurada para un plazo determinado, la cantidad de implementos necesarios para una vivienda que podrla producirse artesanalmente es increible y una vez que se inician estos procesos, el paso a la manufactura y a la industria es mucho más sencillo, todo to cual justificarla una polfica gubemamental de apoyo y fomento a la NEP, ya que no sólo se resolverlan graves problemas sociales, sino que se estarlan generando nuevas fuentes de trabajo y de ingresos.

En opinión de la ONU: "Las posibilidades de la economia popular urbana, son vastos. Si las formas populares de producción han demostrado su capacidad de sobrevivir y competir bajo las más adversas condiciones económicas y con las más inadecuadas estrucluras institucionales, es de prever que dotándolas de un apoyo básico mínimo, puedan encontrar alternativas eficienles de consolidación". "Nosotros, vamos más allá y por ello, hablamos de una Nueva Economla Popular, la cual puede encontrar su primer gran impulso en el Foro de Concertación Económica y Social, en el cual esperamos que se logren, al menos, los siguientes acuerdos:

a) Respeto a las formas de organización y funcionamiento de las distintas comunidades asi como reconocimiento de la realidad irreversible de las cooperativas.

b) Apoyo económico y legal para la constitución de un Sistema Financiero Popular, un Sistema de Capacitación Técnica y Administrativa y un Centro de Coordinación y Planificación Económico Popular, todos con carácter de Corporaciones de utilidad pública y con directores representativos del Sector Popular.

c) Política económica que busque incentivar y proteger a la Nueva Economia Popular en las áreas tributarias, arancelarias y comercial.

d) Agilizar los mecanismos para el reconocimiento de las organizaciones asociativas, ONGs y cualquiera olras formas de inslitucionalidad civil vinculada con la NEP.

- ONU-PNUD, II Conferencia Regional s/la pobreza en América Latina y el Caribe. "Desarrolo sin pobreza". Pág. 126. 
e) Hacer extensiva la seguridad social, vía ISSS, a los integranles de la Economía Popular.

\section{Consideraciones finales}

Esperamos que los anteriores planteamientos encuentren la debida receptividad en lodas aquellas instituciones y organizaciones que se ocupan ya de encontrar salidas viables a las mayorlas populares de nuestro país, así como en las mayorias populares organizadas o no que contorman actualmenle la economia popular o en los gérmenes de la Nueva Economía Popular. Igualmente contiamos en que los tuncionarios públicos y los representantes del sector empresarial capitalisla sabrán comprender la trascendencia de esta iniciativa, que lejos de ser antagónica con su proyecto de sociedad es una estrategia alternativa de y para las mayorias populares, las cuales al lograr mediante su propio estuerzo mejores condiciones de vida y de trabajo, contribuirán de manera significativa a la despolarización, e irán creando las bases para la democracia económica sin la cual, no puede existir la democracia jurídico política.

N.B. Por razones de espacio no citamos profusamente el documento: Desarrollo sin pobreza del PNUD, sin embargo, recomendamos su lectura para una mejor comprensión de nuestro planteamiento. 